\title{
Comunidade de Prática Lusobrasileira na Formação de Professores pela Recriação da Cultura Tecnológica
}

\author{
Adão Caron Cambraia ${ }^{1}$, Uianes Luiz Rockenbach Biondo ${ }^{2}$ \\ ${ }^{1}$ Docente de Computação - Instituto Federal Farroupilha - Santo Augusto - RS - Brasil \\ ${ }^{2}$ Acadêmico de Licenciatura em Computação - Instituto Federal Farroupilha - Bolsista \\ PIBIC (CNPq) - Santo Augusto - RS - Brasil \\ adao.cambraia@iffarroupilha.edu.br, biondouianes@gmail.com
}

\begin{abstract}
The community of lusoBrazilian practice has the objective of analyzing the characteristics of the formative process experienced that provided the Professional Development Teacher in the recreation of the technological culture. The text was developed making an analysis of collective study meetings (recorded and transcribed) with interaction in cyberspace. Also, to illustrate the Brazilian context, publications of works were used. For the analysis of the data used the Discursive Textual Analysis, producing two interconnected categories, which bring indications of a professional development coupled with the re-creation of the technological culture.
\end{abstract}

Resumo. A comunidade de prática lusobrasileira tem o objetivo de analisar as características do processo formativo vivenciado que proporcionaram o Desenvolvimento Profissional Docente na recriação da cultura tecnológica. $O$ texto foi desenvolvido fazendo uma análise de encontros de estudo coletivo (gravados e transcritos) com interação no ciberespaço. Ainda, para ilustrar o contexto brasileiro foi utilizado publicações de trabalhos. Para análise dos dados utilizamos a Análise Textual Discursiva, produzindo duas categorias interligadas, que trazem indicios de um desenvolvimento profissional conjugado com a recriação da cultura tecnológica.

\section{Introdução}

Por meio de uma pesquisa cooperada, no ano de 2018, entre Instituto Federal Farroupilha (Iffar) e o Instituto Politécnico da Guarda (IPG) - Portugal organizamos uma Comunidade de Prática $(\mathrm{CoP})$ para desenvolver a proposta de estudo coletivo sobre a cultura tecnológica na educação e na formação docente. Analisamos a concepção de professores formadores e alunos da Licenciatura em Computação (Brasil) e Licenciatura em Educação Básica (Portugal) sobre como a cultura tecnológica perpassa a formação docente e é integrada ao espaço da escola, proporcionando uma recriação do conceito entendemos por recriação da cultura tecnológica, um alargamento do conceito perpassando cultura digital e construindo espaços para o desenvolvimento do 
VIII Congresso Brasileiro de Informática na Educação (CBIE 2019)

Anais do XXV Workshop de Informática na Escola (WIE 2019)

pensamento computacional. Não se trata de analisar os conceitos em $\mathrm{si}^{1}$, mas entender como a cultura tecnológica se apresenta nos espaços de educacionais. Assim, a problemática de pesquisa é: quais características estão presentes na $\mathrm{CoP}$ de forma a potencializar o desenvolvimento profissional docente pela recriação da cultura tecnológica?

Participaram da CoP lusobrasileira três professores formadores, um egresso e seis alunos do Mestrado em Educação Pré-Escolar e Ensino do $1^{\circ}$ Ciclo do Ensino Básico (CEB) em conjunto com um pesquisador e um bolsista de Iniciação Científica brasileiros. Para a análise da recriação da cultura tecnológica na formação docente foram utilizados dados produzidos por meio de questionários, entrevistas, encontros de estudo coletivo e relatos de experiência com professores e alunos.

Os encontros presenciais e entrevistas foram gravados e transcritos. As interlocuções no ciberespaço são parte dos dados da pesquisa. No lugar dos nomes verdadeiros dos sujeitos da pesquisa utilizamos uma numeração para alunos e professores (professor 1, professor "n" e aluno 1, aluno "n") para evitar a identificação dos mesmos e possíveis constrangimentos. Além do nome fictício, o excerto também foi identificado com o país de origem do membro da CoP. O processo de construção e análise dos dados está pautada na Análise Textual Discursiva [Moraes and Galiazzi 2013], que permitiu identificar relações entre concepções de Desenvolvimento Profissional Docente (DPD) e o processo formativo, categorizando ideias em torno da recriação da cultura tecnológica.

O texto está dividido em duas partes, que são categorias produzidas por meio da análise dos dados. A primeira categoria denominamos "Recriação da Cultura Tecnológica na Educação" e foi dividida em duas subcategorias: cultura digital e pensamento computacional, que serão analisadas no tópico 2. No tópico 3, foi construída a segunda categoria "Desenvolvimento Profissional Docente no Contexto Investigado".

\section{Recriação da Cultura Tecnológica na Educação}

A categoria Recriação da Cultura Tecnológica na Educação é pertinente aos dois cursos de formação. Durante os encontros foi uma temática presente no estudo coletivo. Para organização do texto dividiremos essa categoria em duas subcategorias. Foram utilizadas as nomenclaturas sugeridas pelas Diretrizes para o Ensino da Computação na Educação Básica [SBC 2017]: Cultura Digital e Pensamento Computacional, que possibilitaram o entendimento de como ocorre a presença de cada uma dessas categorias na Educação Básica e na formação de professores, contribuindo também para concretizar uma cultura tecnológica na educação.

A subcategoria Cultura Digital compreende que a comunicação pode ocorrer em qualquer lugar e momento. A internet, bem como os smartphones, permite-nos estabelecer comunicação com outras pessoas em diversos pontos do planeta. Podemos escolher a forma de comunicação, seja através da fala, da escrita ou da imagem. Mudam as formas de comunicação entre as pessoas, que também moldam e determinam a cultura, condicionando novas formas de ser, de viver e se relacionar com os outros e com o mundo, de pensar e fazer educação.

\footnotetext{
${ }^{1}$ Os conceitos já foram exaustivamente discutidos pela comunidade acadêmica em SBC (2017).
} 
VIII Congresso Brasileiro de Informática na Educação (CBIE 2019)

Anais do XXV Workshop de Informática na Escola (WIE 2019)

No contexto da formação de professores em Portugal, conforme relato de professores e alunos do curso, a subcategoria cultura digital prevalece em relação ao pensamento computacional, pois, conforme Professor 1, "o trabalho do semestre dos alunos do mestrado é uma página no wordpress e depois interligamos com o kahoots de diferentes áreas" [p. 22, Portugal], o que demonstra um movimento de transformar a sala de aula num espaço mais comunicacional por meio das tecnologias digitais e a articulação entre diferentes campos do conhecimento.

Por sua vez, no Brasil, como é um curso de Licenciatura em Computação, em que são desenvolvidas atividades que contemplam a cultura digital, como por exemplo: utilização do duolingo para o ensino de língua estrangeira com a metodologia da sala de aula invertida; Responsabilidade e Ética no Virtual são alguns estudos e pesquisas que tratam da presença da cultura tecnológica como uma cultura digital na educação.

A subcategoria Pensamento Computacional contribui para focar no poder de análise, decisão, síntese, organização e estabelecimento de prioridades, pois não se trata apenas da aplicação desenvolvida com computadores, mas sim de uma forma de raciocínio computacional para formulação e resolução de problemas complexos. Tratase da transformação do conhecimento da Ciência da Computação para o conhecimento escolar, envolve a contextualização com os aspectos sociais, culturais, curriculares e políticos, proporcionando novas perspectivas de entender, interpretar e intervir no mundo e transformar a realidade.

Do ponto de vista das aprendizagens dos alunos, o contributo do Pensamento Computacional e Algoritmia passa por elementos tais como i) tornarem-se capazes de identificar aspetos de um problema que sejam suscetíveis de ser implementados através de meios computacionais, ii) tornarem-se aptos a avaliar as limitações e o poder das ferramentas computacionais que utilizam, iii) serem capazes de reutilizar, adaptar e combinar técnicas e estratégias de resolução a novos problemas, iv) saber reconhecer oportunidades para usar ferramentas computacionais em novas formas e com novos objetivos [Portugal DGE 2017].

A Licenciatura em Computação desenvolve atividades para potencializar o pensamento computacional e raciocínio lógico na educação básica, tais como: ensino de programação na educação básica; robótica; computação desplugada; atividades de simulação; salas de aula multifuncionais para a produção de experiências de pensar/produzir tecnologias, tornando o pensamento computacional algo presente no cotidiano escolar.

\section{Formação Docente por meio da pesquisa-ação crítica e emancipatória}

A categoria Formação Docente por meio da pesquisa-ação crítica e emancipatória [Carr and Kemmis 1988] foi elaborada com os materiais produzidos no estudo coletivo (leitura e discussão de textos sobre cultura tecnológica ${ }^{2}$; relatos de experiência de professores). O tópico objetiva analisar a trajetória formativa e a como a cultura tecnológica foi incorporada na educação.

Conforme relatos dos professores portugueses, intensificou-se o trabalho com a computação no início da década de 90, com o projeto Minerva, que "pretendia formar

\footnotetext{
${ }^{2}$ Dentre os textos estudados: SBC (2017) e Portugal (2017).
} 
VIII Congresso Brasileiro de Informática na Educação (CBIE 2019)

Anais do XXV Workshop de Informática na Escola (WIE 2019)

professores na utilização das tecnologias de informação e comunicação. Fornecia um conjunto de contextos aos professores. Teve algum sucesso, mas não teve repercussão em sala de aula, porque não havia recursos" [Professor 2 p. 27, Portugal]. Trata-se de um momento em que os computadores pessoais se tornam mais "populares", universidades e escolas organizam laboratórios de informática e no cotidiano dos professores as tecnologias passam a se tornar presentes. Mas, nessa época a disponibilização de recursos computacionais ainda é escassa ou pelo menos o acesso dos professores ainda é difícil no sentido de integrar as tecnologias digitais e construir relações com a educação.

Nesses projetos de formação contínua se ensinava o básico. Fazíamos formação sobretudo na utilização de ferramentas que de alguma forma melhorasse a sua atividade como professor. Nunca com um propósito, poucas vezes havia projetos, mas poucos eram operacionalizados, não tinha adesão por parte dos professores [Professor 2 p. 27, Portugal].

No contexto escolar brasileiro não era diferente. O que geralmente ocorria era a criação de cenários de usos: projetos educacionais; jogos eletrônicos; softwares educacionais e internet [Cambraia 2015]. As dificuldades de formação docente eram semelhantes ao contexto português. Implicando na dificuldade do desenvolvimento da cultura digital na escola e, dificilmente, ocorria aproximações ao pensamento computacional.

No final da década de 90 e início de 2000, o governo Português propôs o projeto Internet na escola. [...] Tínhamos dinheiro para comprar 10 computadores e fazermos dez ligações. Foi uma loucura, porque foi uma guerra para decidir qual escola seria contemplada. O projeto demorou para ter sucesso e foi implementado a nível nacional. Todas as escolas receberam computador. [Professor 2 p. 27, Portugal].

$\mathrm{Na}$ década de 90 e, primeiros anos de 2000, a cultura digital foi potencializada e havia instituições que faziam um enorme esforço para receber um laboratório de informática. No Brasil, os computadores foram "popularizados" por meio do Programa Nacional de Tecnologia Educativa (Proinfo).

Em Portugal, segundo o professor pesquisador sobre cultura digital, iniciou-se uma nova etapa com o projeto Magalhães. Tratou-se da distribuição de computadores de pequeno porte para alunos utilizarem no dia a dia. "O computador Magalhães não funcionou, as escolas não estavam preparadas. $O$ professor destaca uma dificuldade de formação docente - "as escolas não estavam preparadas" - significa que os professores não receberam formação para integrar cultura digital na educação ou se receberam não era suficiente para inovar em sala de aula.

Por sua vez, no Brasil, um projeto semelhante ao Magalhães é o projeto Um Computador por Aluno (UCA) implementado no ano de 2007 e em 2010 foi modificado para Programa um Computador por Aluno (PROUCA), alcançando 300 escolas no país. Lang (2016), destaca que no PROUCA, o uso das tecnologias nem sempre estiveram direcionadas a modificar as experiências de aprendizagem, sendo muitas vezes utilizadas com o propósito de fortalecer o processo tradicional de ensino.

Dessa forma, A CoP Lusobrasileira, por meio da pesquisa-ação crítica e emancipatória, é uma forma de transformar essa trajetória e proporcionar a recriação da cultura tecnológica na Educação, pois como se percebe nos relatos anteriores a cultura digital predomina e não há indícios de priorizar também o desenvolvimento do 
VIII Congresso Brasileiro de Informática na Educação (CBIE 2019)

Anais do XXV Workshop de Informática na Escola (WIE 2019)

pensamento computacional. Foi com esse intuito que foi proporcionado o planejamento de projeto integrador com abordagem temática iniciado durante a pesquisa cooperada, organizado e planejado de forma colaborativa na CoP Lusobrasileira, concretizando estudos coletivos para a recriação da cultura tecnológica, potencializando a indissociabilidade entre cultura digital e pensamento computacional.

\section{Considerações Finais}

Na categoria Recriação da Cultura Tecnológica na Educação ocorreu um "alargamento" da compreensão do conceito, que, inicialmente, partiu do entendimento de que era sinônimo somente da cultura digital. Como se percebe no texto grande parte dos professores formadores e, por consequência, na educação básica predomina a cultura digital e, dificilmente, ocorre uma indissociabilidade com pensamento computacional. Após o estudo coletivo foi possibilitado novas compreensões, aproximando-se da categoria pensamento computacional. O "alargamento" do conceito cultura tecnológica perpassando a cultura digital e pensamento computacional é o que chamamos de recriação da cultura tecnológica, entendendo essas categorias como indissociáveis. Uma mudança de concepção dos professores, que proporciona o DPD, que é defendido como primordial para possibilitar aprendizagens permanentes dos professores formadores e em formação.

\section{Referências}

Cambraia, A. C. (2015). A presença da cultura informática nas escolas. In: Publicatio UEPG: Ciências Sociais Aplicadas, v. 23, p. 71-89.

Carr, W. and Kemmis, S. (1988). Teoría crítica de la enseñanza, Barcelona: Martins Roca.

Lang, A. M. R. (2016). O Desenvolvimento Do Conhecimento Pedagógico Tecnológico Do Conteúdo De Professores Do Ensino Fundamental. Dissertação de mestrado pela Universidade Estadual Paulista. UNESP. Orientado por: Fernando Jaime González.

Moraes, R. and Galiazzi, M. C. (2013), Análise Textual Discursiva, Ed. UNIJUÍ, $2^{\text {th }}$ edition.

Portugal, D. G. E. (2017), "Probótica - Programação e Robótica no Ensino Básico Linhas Orientadoras", http://www.erte.dge.mec.pt/sites/default/files/probotica__linhas_orientadoras_2017.pdf, March.

Sociedade Brasileira de Computação (SBC) (2017), "Referenciais de Formação em Computação: Educação Básica", http://www.sbc.org.br/documentos-da$\mathrm{sbc} / \mathrm{send} / 131$-curriculos-de-referencia/1166-referenciais-de-formacao-emcomputacao-educacao-basica-julho-2017, March. 